\title{
Impact of antiretroviral therapy on household economics: Findings from Mombasa, Kenya
}

Rick Homan

Desai Jaikishan

Paul Munyao

Avina Sarna

Population Council

Scott Geibel

Population Council

Follow this and additional works at: https://knowledgecommons.popcouncil.org/departments_sbsr-hiv

Part of the Demography, Population, and Ecology Commons, Family, Life Course, and Society Commons, International Public Health Commons, and the Medicine and Health Commons How does access to this work benefit you? Let us know!

\section{Recommended Citation}

Homan, Rick, Desai Jaikishan, Paul Munyao, Avina Sarna, and Scott Geibel. 2007. "Impact of antiretroviral therapy on household economics: Findings from Mombasa, Kenya," Horizons Research Summary. Nairobi: Population Council. 


\section{IMPACT OF ANTIRETROVIRAL THERAPY ON HOUSEHOLD ECONOMICS: Findings fRom Mombasa, Kenya}

A longitudinal study of clients on antiretroviral therapy (ART) found that perceived health improved, reported incidence of illness and use of health services declined, and labor force participation increased within 12 months of initiating therapy. These findings support the value of ART in helping individuals be productive members of their households and society.

\section{V}

Thile the clinical impact of receiving ART on persons living with HIV is well documented, less is known about how the receipt of ART affects household economics. In this analysis, we examined the direct and indirect effects of receiving ART on household economics. A direct effect is reduced spending on health services as a result of the improved health status of the household member on ART. The potential indirect effects include increased labor force participation by the household member on ART, a change in how other household members spend their time (working or in school), and a shift in the composition of household expenditures. This summary describes the experiences of a cohort of

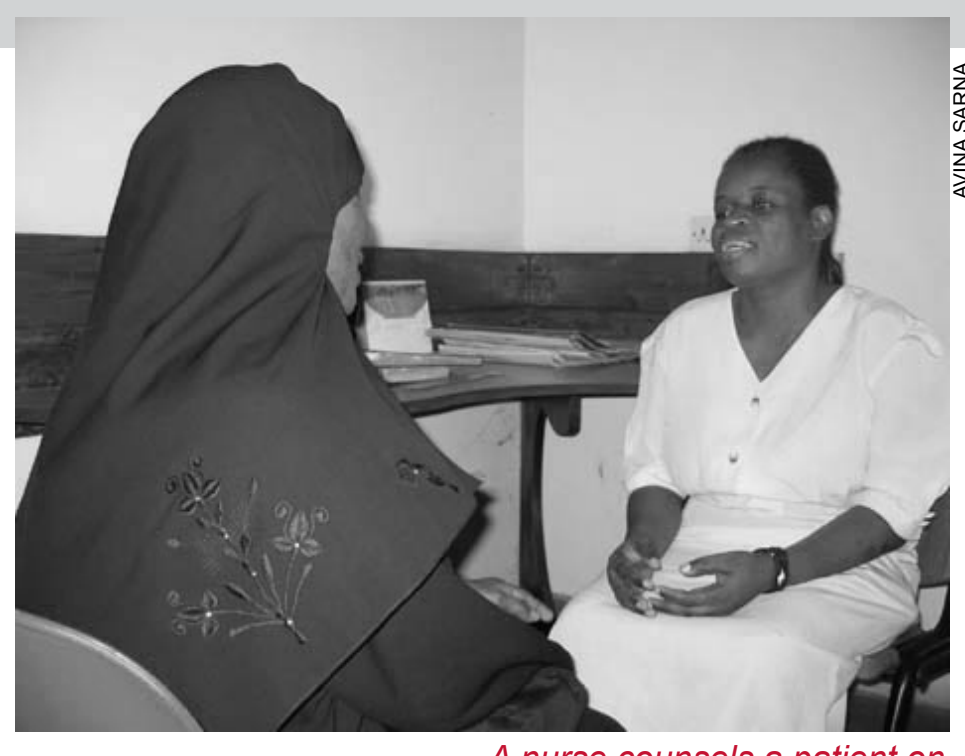

A nurse counsels a patient on antiretroviral therapy in Mombasa, Kenya. people living with HIV who were receiving ART through a program coordinated by the Coast Provincial General Hospital (CPGH) in Mombasa, Kenya ${ }^{1}$.

\section{Methods}

Two hundred and thirty-four index clients who were receiving HAART from the program established through CPGH were recruited for participation in a longitudinal study of health and household economics. Clients were interviewed at baseline

To read more about this study, go to www.popcouncil.org/horizons/projects/Kenya_HAARTMombasa.htm
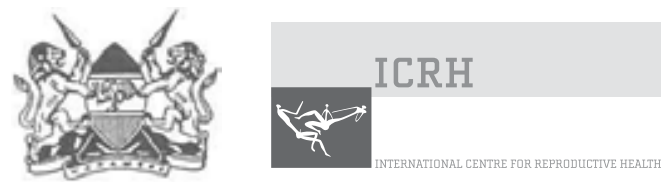
beginning in September 2003, and six months $(\mathrm{n}=189)$ and 12 months $(\mathrm{n}=$ 178) after recruitment. At baseline, 64 percent $(n=150)$ of index clients were female, and half of female clients and 79 percent of male clients identified themselves as the head of their household.

The interviews were conducted in two parts. The first part was conducted at the clinic and the second more extensive interview took place in the client's home. In some cases only the clinic interview was completed. The clinic-administered instrument focused on client demographics, client health perceptions and use of health services, client employment status and income, and perceptions of change due to receipt of ART. The household instrument focused on the entire household and examined the education, health, and employment status of household members, the sources of household income, and the uses of income and assets over the prior six months.

By looking at responses over time, we were able to assess changes at the household level. But it is important to note that not all changes observed were solely due to the receipt of ART. Many observed changes could be due to other factors, such as non-HIV related illnesses such as malaria, accidents, and injuries, or a person leaving the household for employment in another locale. Income and expenditure reports are especially vulnerable to such influences; therefore we focus on the composition of income or expenditures rather than the magnitudes reported.
Our analysis focused on three aspects: 1) changes in the incidence of illness and use of health services by index patients, 2) changes in labor force participation by clients and other household members, and 3) shifts in the magnitude and composition of household expenditures.

\section{Results}

Index clients reported almost immediate perceived improvements in health associated with the receipt of HAART. These perceptions persisted even after the initial 6-month period in which the most dramatic health responses occurred. At baseline, over 40 percent of index clients reported that their health had been declining over the prior six months (see Figure 1). At the 6-month follow up, over 90 percent reported that their health had been improving over the prior six months and at the 12-month follow up, over 75 percent reported that their health continued to improve over the prior six months. Whether or not this corresponds to clinically detectable improvements in health (e.g., CD4 counts, weight gain, etc.), it has important psychological ramifications as the client was more likely to have an optimistic attitude toward his or her health which may have important implications for adherence to medications and workforce participation.

The index clients reported a 50 percent reduction in reported illness incidence over the 12 -month period (see Figure 2). Because they have a chronic disease,

Figure 1 Perceptions of current health compared to health in the previous six months at baseline and follow up

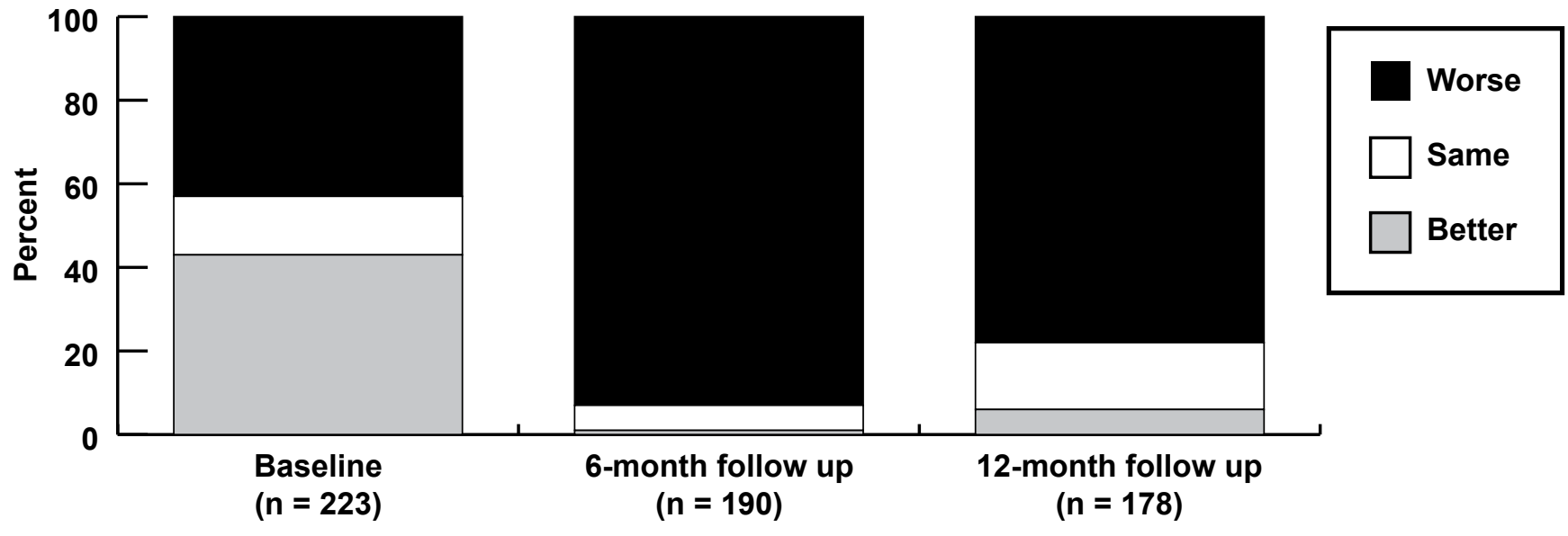


Figure 2 Illness incidence and use of services by index

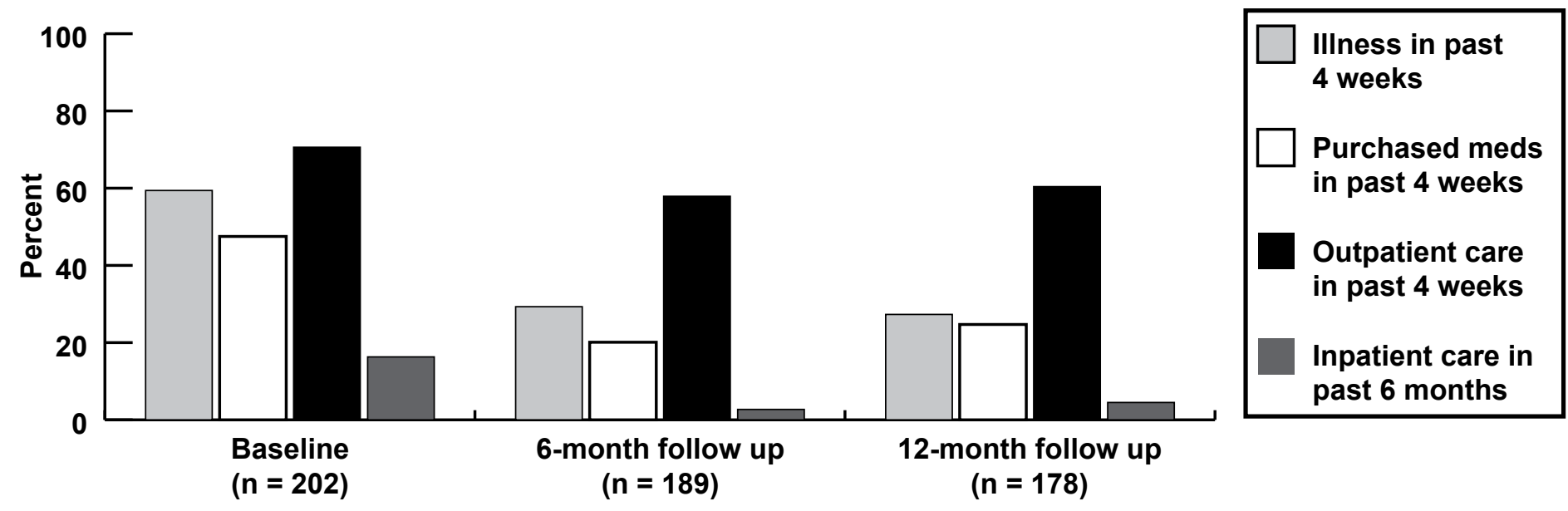

there was a less dramatic reduction in the use of outpatient services, because even when healthy they are likely to return to the clinic for monitoring. Medication purchases and inpatient utilization decreased substantially. Prior to enrollment in the program, many clients had been symptomatic and were seeking care from many sources. The reduction in inpatient utilization may be due in part to patients who came to know about their HIV status during a hospitalization. With the enrollment in the program we would expect to see more effective use of medical services due to the receipt of counseling and support services and to the beneficial effects of being on ART.

In terms of labor force participation, we observed a gradual return to the workplace by index clients. At baseline, 56 percent of index clients $(72$ percent of males and 48 percent of females) had done some work in the last 6 months and contributed 65 percent of the total hours worked by the household. At six months, labor force participation increased to 63 percent $(75$ percent of males and 56 percent of female) and the hours contributed rose to 70 percent. At 12 months, 64 percent of index clients had worked in the past six months (75 percent of males and 58 percent of females), and their hours worked accounted for 68 percent of the hours worked by the household. The male index clients increased their share of household labor from 55 percent at baseline to 77 percent at 12-months, while the female index clients reported a small reduction in their share of household labor from 71 percent at baseline to 65 percent at the 12 -month follow up. In addition to the index clients increasing their role as household earners, there were small increases in the number of household members per worker over the period which suggests that the index clients return to more stable health made their ability to contribute to the household all the more important, allowing them to compensate for the loss of work by other household members or the return to school by adolescents.

Over the 12-month period, reported household expenditures decreased by 17 percent. As mentioned above, this may be the result of random variation; but when the composition of household expenditures is examined, there was a dramatic decrease in the share devoted to health services (from 12 percent of total at baseline to 3 percent of total at 12 months). The other categories also showed small changes over time but nothing as dramatic. The implication of this marked reduction (almost 20,000 KSh. or USD257 for a 6-month period ${ }^{2}$ ) in reported expenditures is that households may be able to gradually increase their savings or reduce their debt and slowly improve their economic position.

\section{Discussion}

It should be kept in mind that our results were based upon a small sample of clients $(\mathrm{n}=234$ at baseline) and that the time horizon was relatively short (12 months). However, even in this context there is evidence to support our hypotheses. We saw dramatic improvements in perceived health, a corresponding reduction in the reported incidence of illness among our index clients, reduced expenditures on health care services both for index clients and also for other family members, and 
the potential for increased savings or debt reduction at the household level. Some of the reduction in health spending for other household members is perhaps due to more appropriate use of health services. While on the surface it doesn't seem likely that other household members would become healthier as a result of the index patient receiving ART, it is possible that as clients become integrated into the comprehensive care center at Coast Provincial General Hospital, their knowledge of health improves and this may influence the health behaviors of the other household members as well. Another way to account for reduced health spending even without a reduction in the incidence of illness is by changing the source of care from the more expensive private sector to the public sector. Since the client is now integrated into public-sector care at $\mathrm{CPGH}$, the other household members may have been more inclined to seek services there as well.

Since the majority of our index clients were the heads of households, their ability to reenter the labor force and gain income to support the household is critical. In addition, the ability to reduce the magnitude of health care expenditures by about 80 percent and overall household expenditures by 17 percent suggests that these households may be able to avoid slipping further into debt and position their children for a brighter future. A positive outlook for the future may be the best prevention message of all, as people behave in ways to plan for and protect the future rather than reacting to the immediate situation and hoping things will change. The increased availability of ART has been an important part of giving people living with HIV hope for the future and confidence in their abilities to be productive members of the household and contribute to the overall economy. This is the long-term goal of increased access to ART - that people living with HIV can con- tinue to be productive members of society and that the overall economy can continue to grow to the benefit of all citizens. In our small sample, we see evidence to suggest this hope is possible and that through continued support and expansion of these types of programs, the benefits can reach more households. $\mathcal{X}$

December 2007

${ }^{1}$ For a more complete description of the overall program, please see: Munyao, P. et al. 2005. "How feasible is a DAART strategy to promote adherence to ART?: Lessons from Mombasa, Kenya," Horizons Research Update. Nairobi: Population Council.

${ }^{2}$ Based upon historical exchange rates for period reported (9/1/03 to 4/30/05) Source: http://www.oanda.com/convert/ fxhistory

Investigators for this study were Rick Homan and Jaikishan Desai of Family Health International (FHI), Paul Munyao of the International Centre for Reproductive Health (ICRH), and Avina Sarna and Scott Geibel of Horizons/Population Council. Intervention and study partners include Horizons, ICRH, Coast Province General Hospital, Mkomani Bomu Clinic, Port Reitz District Hospital, FHI/IMPACT, MSH/RPM Plus, and Kenya Ministry of Health.

Suggested citation: Homan, Rick, Jaikishan Desai, Paul Munyao, Avina Sarna, and Scott Geibel. 2007. "Impact of antiretroviral therapy on household economics: Findings from Mombasa, Kenya," Horizons Research Summary. Nairobi: Population Council.

\section{Hqrizons} Population Council/Horizons Communications Unit 4301 Connecticut Avenue, NW Suite 280 Washington, DC 20008

\section{P Population Council}

Tel: $202-237-9400$

Fax: 202-237-8410

horizons@popcouncil.org

www.popcouncil.org/horizons
This research summary is made possible by the generous support of the American people through the United States Agency for International Development (USAID) and the President's Emergency Plan for AIDS Relief under the terms of HRN-A-00-97-00012-00. The contents are the responsibility of the Horizons Program and do not necessarily reflect the views of USAID or the United States Government. 